\title{
FEIJOO, CRITICO DE LA EXEGESIS MITOLÓGICA
}

Fuente inagotable y constante para poetas, pintores y escultores, la mitología grecorromana, con su cortejo de figuras graciosas o terribles, nunca ha dejado de cumplir con su papel de inspiradora, de tal modo que, por lo menos hasta el romanticismo, costaría trabajo descubrir a un autor que no haya acudido al panteón clásico para ilustrar su pensamiento y enriquecer su arte.

Más allá del interés estético que despertaba, la mitología no tardó tampoco en excitar curiosidades más eruditas: filósofos, sabios filólogos, historiadores de las religiones trataron ya en época temprana de penetrar el secreto de las aventuras galantes o guerreras de las divinidades del Olimpo. Y muy temprano también, el cristianismo tuvo que enfren. tarse al recuerdo tenaz del paganismo y sintió la necesidad de combatir la mitología o, por el contrario, de asimilársela descubriendo en sus misterios la huella de una revelación parcial y mal interpretada.

Dos sistemas principales de explicación de las fábulas gozaron de una fortuna apreciable. El primero nos lo ofrece la antigüedad misma, una antigüedad que no cree ya en sus dioses y trata de justificar sus mitos: es el evemerismo, método de interpretación que consiste en identificar, bajo la máscara de los héroes mitológicos, a personajes reales, elevados por la credulidad del vulgo o la imaginación de los poetas al rango de divinidades. Filóstrato, Plinio y Diodoro Sículo se esfuerzan por dar explicaciones razonables y materialistas de las fábulas y por descubrir en ellas una verdad que la tradición ha desfigurado. Estas explicaciones le convenían perfectamente al cristianismo, de manera que gozaron de mucho favor entre los Padres de la Iglesia, a los cuales "el evemerismo ofrecía a la vez una conciliación satisfactoria con el legado clásico y un argumento cómodo contra la idealización peligrosa de los dioses clásicos ${ }^{1}$. Los más grandes dan el ejemplo: para San Agustín, Mercurio fue un hombre tan hábil que la gente lo hizo dios, se decía que Minerva había nacido de la cabeza de Júpiter porque se había hecho ilustre por varios inventos útiles, y Prometeo fue un sabio egipcio, contemporáneo de Esculapio y de Licurgo. El obispo de Hipona no es el único que se empeña así en minar las bases del paganismo. Cosas análogas se leen en Clemente de Alejandría, Eusebio, Lactancio, Isidoro de Sevilla y otros muchos.

El Renacimiento presenció una proliferación de exegetas y mitólogos. Entre varios otros sistemas de interpretación, el evemerismo conserva su lugar; las explicaciones "históricas" heredadas de la antigüedad y perfeccionadas por los Padres siguen vigentes en los manuales de Comes, de Cartari o de Gyraldi y en los diccionarios de Estienne. En el siglo xvn, el evemerismo triunfa en La vérité des fables, ou l'histoire des dieux de l'antiquité (1648), intento de reconstrucción, por Desmarets de SaintSorlin, del famoso libro de Evémero. Así, a lo largo de veinte siglos, había sobrevivido un método de explicación de la fábula sin debilitarse

1. O. Ragcio, "The myth of Prometheus. Its survival and metamorphoses up to the 18th century", JWC, 21 (1958), p. 51 . 
nunca, pese a la competencia de los sistemas morales, alegóricos o herméticos; y ya nos volveremos a encontrar con él en el Siglo de las Luces.

Paralelamente al evemerismo, otro modo de exegesis estaba destinado a tener un éxito prodigioso. Hacía de la mitología entera una copia adulterada de la Escritura, un plagio cuyo origen se perdía en el tiempo; siendo la Biblia el texto más antiguo del mundo, era natural que hubiera inspirado todas las supersticiones paganas, las cuales resultaban ser una traición de la verdad revelada. A partir de la unidad original, hubo un proceso de degradación, de corrupción; analizar este proceso es servir a la ciencia y servir a Dios. Entre los Padres, hasta hombres tolerantes como Justino, Clemente de Alejandría, Orígenes o Agustín sostienen que los griegos no hicieron más que entrar a saco en la sabiduría hebraica. Así Pandora, según Tertuliano, es el disfraz pagano de Eva; la creación del hombre por Prometeo disimula, según Lactancio, la creación del hombre por Dios. Así, pues, se puede hablar de una cristianización de los mitos griegos, ya que la mitología tiende rápidamente a "conciliarse con la teología": "el genio alegórico de la Edad Media, que, renovando la tradición de los Padres, descubre en los personajes y episodios del Antiguo Testamento prefiguraciones de la Nueva Alianza, entrevé en los personajes y episodios de la fábula prefiguraciones de la verdad cristiana"'2. Al mismo tiempo que el evemerismo, y a menudo, paradójicamente, en los escritos de un mismo autor, la asimilación de los personajes mitológicos a los bíblicos conquista un éxito duradero.

Este método atravesará todo el Renacimiento en las pesadas compilaciones eruditas de los mitólogos, inspirando de paso a no pocos poetas. Pero no triunfa verdaderamente sino en el siglo xvn: con sabios como Bochart, Vossius, Heinsius, Kircher, Thomassin y Huet, la búsqueda de un estrecho paralelismo entre los temas bíblicos y los mitológicos adquiere una importancia excepcional. Los dos sistemas de explicación de la fábula tienen, pues, en los albores del siglo xvin, un derecho de ciudadanía varias veces secular. Y contra las dos tradiciones, a pesar de hallarse profundamente arraigadas, no tardará en emprender una guerra el P. Benito Jerónimo Feijoo.

Para apreciar mejor el mérito de su intervención y subrayar más su originalidad, conviene, sin embargo, esbozar un breve resumen del estado de la exegesis mitológica en el siglo ilustrado, y examinar qué vitalidad mantenían aún las dos teorías en cuestión.

El evemerismo gozaba, evidentemente, de buena salud. Las narraciones legendarias de los antiguos - se decia - son testimonios acerca de los tiempos remotos, anteriores a toda tradición escrita; así, concluía Nicolas-Antoine Boulanger, la mitología "es una de las mayores autoridades que pueden hallarse sobre tan oscuro tema"3. Por su parte, el abate Banier, principal representante de la interpretación histórica, veía en ella "historias de los tiempos remotos, desfiguradas por la ignorancia

2 J. SEZNEC, La survivance des dieux antiques, London, 1940, pp. 81-82.

3 Essai philosophique sur le gouvernement, où l'on prouve l'influence de la Religion sur la Politique, Londres, 1788, p. 29. Desarrolla la misma opinión en L'Antiquité dévoilée par ses usages, Amsterdam, 1766. Cf. t. 1, p. 20: "ees fables ou ces énigmes sont les seuls monumens qui nous restent des premiers tems”. 
de los pueblos, o por el artificio de los sacerdotes, o por el genio de los poetas, que siempre han preferido lo brillante a lo sólido"4. Minerva, por ejemplo, fue una auténtica princesa famosa por su ciencia, Prometeo "un príncipe sabio y cultísimo" que civilizó a los escitas, Atlas un astrólogo célebre, Hércules el iniciador griego de la astronomía, ciencia ilustrada, en Italia, por Faetonte. Gracias al proceso de la divinización, observaba el abate de Tressan, "el recuerdo de los mayores acontecimientos" nunca llegó a perderse, y los antiguos que, en su corrupción, se dieron a inventar dioses, confundieron en un solo relato "las verdades históricas y la historia fabulosa de las divinidades" 5 . Como se ve, el evemerismo no había perdido nada de su vigor y de su importancia, y es, por cierto, el sistema oficial de la Encyclopédie.

Sin embargo, la asimilación de los personajes mitológicos a los bíblicos conservaba sus partidarios, y a principios del siglo xvnr la idea de que los mitos griegos eran una contrahechura de las verdades cristianas parecía ser "una convicción general"6. La tesis más aceptada es la de un monoteísmo original que, a consecuencia de la corrupción de la humanidad, se fue borrando poco a poco de la memoria de los hombres, salvo en el pueblo elegido. Con todo, el cielo les dejó a los paganos una oportunidad de entrever la verdad; así se explican, según Guillaume de Lavaur, las contradicciones internas del paganismo: "Dios no se dejó a sí mismo sin testimonio en medio de las naciones paganas [...]. Sembró los errores del paganismo de tantas y tan evidentes contradicciones, que los paganos que quisieron prestarles atención quedaron impresionados por ellas"'. Del postulado de la anterioridad absoluta de la Biblia y de la vieja tesis patrística de la condescendencia y de la revelación parcial, se concluye la posibilidad de descubrir en todas partes personajes sagrados: "Reducid la teología pagana a sus verdaderos principios -escribía ya Benjamin Binet-, y hallaréis que toma del judaismo la mayor parte de sus misterios" 8 . Parece, pues, un axioma que "toda la

4 Explication historique des fables, où l'on découvre leur origine et leur conformité avec l'histoire ancienne, $2^{\mathrm{e}}$ éd., Paris, 1715, t. 2, pp. 18-19. En 1686, en sus Entretiens sur la pluralité des mondes ( $6^{\mathrm{e}}$ soir), Fontenelle observaba también: "Les Fables ne sont point tout à fait des Fables; ce sont des histoires des temps reculés, mais qui ont été défigurées, ou par l'ignorance des peuples, ou par l'amour qu'ils avaient pour le merveilleux, très ancienne maladie des hommes".

" La mythologie comparée avec l'histoire, nouv. éd., Paris, 1804, t. 1, p. 9. Cf. También MME. DE Genlis, Arabesques mythologiques, Paris, 1810, p. v: "la vérité, premier principe de toutes choses, a d'abord formé le fond de cet étrange mélange [= la mitología]. Il n'est pas douteux que l'Histoire a servi de base à la Fable".

6 Cf. O. GRUPPE, Geschichte der klassischen Mythologie und Religionsgeschichte während des Mittelalters und während der Neuzeit, Leipzig, 1921, p. 58. En realidad, ciertos filósofos sostienen todo lo contrario. "Si l'on voulait se donner le peine - dice Voltaire- de comparer les événements de la fable et de l'ancienne histoire grecque, on serait étonné de ne pas trouver une seule page des livres juifs qui ne fût un plagiat". Véase, sobre esto, "Voltaire et la mythologie", BBudé, 1962, pp. 222-229; y sobre la utilización, por los filósofos, de la mitología como arma contra el cristianismo, "De quelques significations de la mythologie au xvir ${ }^{\mathbf{e}}$ siècle", Bull. de l'Institut Voltaire de Belgique, 1963, núm. 15, pp. 137-145.

7 Guillaume de Lavaur, Conférence de la Fable avec l'Histoire Sainte, Paris, $173^{\circ}$, t. 1 , pp. $5^{-6}$.

8 B. Binet, Ldée générale de la théologie payenne, Amsterdam, 1699, p. 28. 
mitología griega no es sino una traducción alterada de la Escritura"9. Siguiendo el ejemplo de los grandes eruditos del siglo anterior que habían fundado la exegesis comparatista, se harán toda clase de identificaciones: Jápeto $=$ Jafet, Baco $=$ Noé, Hércules $=$ Sansón, Prometeo $=$ Moisés (o Abel o Magog), Pandora $=$ Eva, no sin acudir a las luces de la filología y de la etimología para apuntalarlas ${ }^{10}$.

Tal es, pues, el estado de la exegesis mitológica en el momento en que Feijoo redacta su enciclopédico Teatro critico universal. Un hombre cuyo sentido crítico siempre alerta abarcaba todas las actividades del espíritu y que se había fijado como meta el "desengaño de errores comunes", no podía menos de sentirse asombrado por el frenesí sistemático que dominaba en la interpretación de las fábulas y por la obstinación fanática que demostraban, desde el Renacimiento, los eruditos franceses e italianos ${ }^{11}$. Ya que el evemerismo y la asimilación a los personajes bíblicos se presentaban como sistemas, y ya que los dos métodos de interpretación dominaban la exegesis por la fuerza de una tradición multisecular que nadie hubiera pensado en criticar sino en función de otro sistema igual de inflexible, el P. Feijoo tenía que considerar la mitología como un pretexto de importancia para ejercitar su escepticismo. Y en dos ocasiones se ocupa del asunto: primero en el Teatro, discurso $8^{\circ}$, "Divorcio de la historia y la fábula", y luego en las Cartas eruditas, carta XLII, "Origen de la fábula en la historia"12.

El discurso del Teatro crítico está consagrado a un apretado análisis de la identificación de los héroes mitológicos con los personajes de la Escritura. Una tradición común a los eruditos y al vulgo supone "que la fábula siempre se fabrica sobre el cimiento sólido de alguna verdad histórica". Partiendo de tan gratuita hipótesis, sabios como Bochart, Huet, Tournemine, Heinsius y Vossius han pretendido que las fábulas no podían ser sino alteraciones de la Verdad, y sobre tal convicción han escrito volúmenes de conjeturas eruditas. De golpe, Feijoo asegura que "todo fue cultivar con grande afán una tierra que no podía producir sino flores: quiero decir, que todas las fatigas de estos grandes hombres sirvieron a ostentar su ingenio y erudición, mas no a descubrir la ver-

9 Pierre Guérin du Rocher, Histoire véritable des temps fabuleux, Paris, 1776 , t. 1, p. 67. Cf. asimismo G. DE Lavaur, op. cit., t. 1, pp. 78-79.

10 Citemos, entre otros, a G. DE Lavaur, op. cit., t. 2, p. 62, a propósito de Niobe: "On y reconnaît l'histoire véritable de Job [...]. Les Grecs [...] ont composé ce nom de deux mots grecs qui ne veulent rien dire autre chose que la femme de Job; Nuos, c'est-à-dire épouse, à quoi l'on a joint le nom même de Job, dont on a fait Nuiobou, femme de Job".

11 Feijoo no cita a ningún mitólogo español. Pero había habido dos, bastante conocidos, a los cuales, por cierto, acudió Calderón para la elaboración de sus obras teatrales de tema mitológico: Juan Pérez de Moya (Philosophia secreta, donde debajo de historias fabulosas se contiene mucha doctrina provechosa, 1585), que se inspira directamente en el italiano Natale Conti, y fray Baltasar de Victoria (Teatro de los dioses de la gentilidad, 1620), compilación hecha a base de Ravisio Textor, Alciato, Conti, Cartari y Boccaccio.

12 Teatro critico universal, o Discursos varios en todo género de materias, para desengaño de errores comunes..., 3. ed., Madrid, 1742-1749, t. 5, pp. 159-179; Cartas eruditas y curiosas, Madrid, $1774^{-1775}$, t. 1, pp. 319-329. (En nuestras citas, modernizaremos la acentuación, la puntuación y el uso de mayúsculas). 
dad", dictamen severo que Feijoo se propone demostrar mediante el simple recurso de "apelar a la razón".

Admiremos, nos dice, la poca armonía que reina entre los partidarios del comparatismo bíblico: Hércules representa a Josué según unos, a Adán según otros; Perseo es ora Moisés, ora Jonás. En cuanto a él, nos propone estudiar, por ejemplo, las interpretaciones del mito de Prometeo, tal como aparece en la Demonstratio evangelica de PierreDaniel Huet, obispo de Avranches, y en el Projet d'un ouvrage sur l'ori. gine des fables, del P. Tournemine ${ }^{13}$.

Con respecto a Tournemine, que pretendía explicar las fábulas para "dar a conocer las verdades que nos ocultan", Feijoo se contenta con una demolición rápida, ya que el método elemental del jesuita no le parecía digno de retener largamente la atención. Tournemine aseguraba: "c'est Lucifer dont les Anciens ont voulu nous conserver l'histoire sous le nom de Prométhée", ya que en las aventuras del Titán "on voit de manifestes allusions au péché des Anges, et à celui du premier homme". Tales argumentos, replica Feijoo, no descansan en nada: ¿en qué autor antiguo leyó Tournemine que Prometeo tenía envidia de su hermano, lo cual debía representar a Luzbel celoso de Adán ${ }^{14}$ ¿Y de dónde sacó que Prometeo sugirió a Epimeteo que abriese la caja de Pandora, transponiendo así la tentación de Adán por Luz-

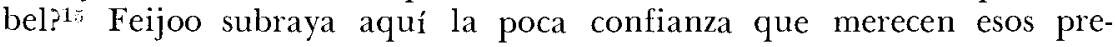
tendidos sabios: cuando no hallan argumentos, los inventan. Además -y aquí Feijoo da una lección de crítica histórica-, el testimonio único de un autor antiguo no puede bastar para fundamentar una certidumbre, y, sobre todo, no hay base para generalizar su opinión: "no se debe o puede usar, en esta materia, de la ficción particular de un poeta como si fuese error común del gentilismo".

Feijoo se ocupa en seguida de Huet, a quien concede los honores de una larga demostración, refutándolo a la vez en el plano mitológico y en el bíblico. Es verdad que Huet merecía su atención: discípulo de Samuel Bochart, no da menos de trece "pruebas" diferentes de la identidad (indiscutible, según él) de Prometeo y Moisés. Feijoo las examina pacientemente una por una y, cada vez, pone en evidencia la debilidad de su razonamiento. Veamos sólo los ejemplos más significativos.

Heródoto, refiere Huet, asegura que Prometeo fue marido de Asia; ahora bien, Moisés fue oriundo de Asia ${ }^{16}$. Absurdo, exclama Feijoo: se trata, en Heródoto, de la ninfa asi llamada, no del continente. Prometeo tuvo algunos coloquios con Júpiter, y Moisés los tuvo con Dios ${ }^{17}$; según

${ }_{13}$ Demonstratio evangelica ad Serenissimum Delphinum, editio altera, Amstelorlami, 1680, Prop. IV, cap. viII, 7, pp. 162-166 ("Prometheus idem ac Moses"); "Projet d'un ouvrage sur l'origine des fables", Mémoires de Trévoux, nov.-déc. 17o2, p1). 84-111 y ("Addition", pp. 1-22).

${ }^{14}$ Seria, en efecto, más bien lo contrario: cf. Platón, Protágoras, 320c-321c.

1. Aqui también es lo contrario, ya en Los trabajos y los dias de Hesiodo.

16 Demonstratio, p. 162: "Asiae maritum fuisse narrat Herodotus: ex Asia oriundus fuit Moses, totaque Israëlita gens in Asiam ex Aegypto remeavit".

17 Ibid., p. 163: "Cum Jove colloquia Prometheus habuisse fertur: Mosem Dei bagtodis fuisse constat". 
eso, comenta Feijoo, todos los personajes de la mitología que dirigieron la palabra al señor de los dioses representan a Moisés. Se dice en algún lugar que Prometeo creó a los hombres, porque les dio leyes: ¿no es ésa una clara alusión a la legislación de Moisés?:18 Ciertamente, sonríe el autor del Teatro, y alusión también muy clara a Rómulo, Numa Pompilio, Minos, Dracón, Solón, Licurgo "y todo el Areópago". En resumen, concluye Feijoo, tales afanes son quiméricos, no descansan en nada; lejos de proceder de un verdadero espíritu científico, no son sino una manera falaz de confirmar un sistema preexistente: "TTerrible es el prurito de buscar alusiones!"

De hecho, esta exegesis comparatista no tiene, las más de las veces, ningún fundamento: "es quimérica la empressa de descubrir las verdades de la Escritura en los errores de el gentilismo". Peor aún, es ir contra el testimonio mismo de los textos sagrados. Al descubrir a todos los dioses del paganismo en Moisés y a todas las diosas en Séfora, Huet sostiene que Moisés fue anterior a todas las fábulas paganas, a las cuales sirvió de modelo. Pero la Biblia misma dice expresamente que había idolatrías mucho tiempo antes de Moisés, e incluso en sus tiempos la idolatría estaba extendida en muchísimas naciones. No contento con desfigurar la fábula, Huet consigue así traicionar esas Escrituras so pretexto de ilustrarlas. He ahí adónde conduce el espíritu de sistema, a qué excesos llega el hombre cuando prescinde del uso de su razón. Convencido de servir a la causa del cristianismo eterno, Huet le causa en realidad el mayor perjuicio en el espíritu de quienes juzgan una fe de acuerdo con aquellos que la defienden. Para terminar, Feijoo no vacila en oponer al sistema de Huet otro sistema; y su solución, como su crítica, será la del buen sentido y la mesura:

Possible es [...] que una u otra de las historias sagradas, degenerando poco a poco de su pureza, según que o la malicia o la ignorancia de los hombres fue o quitando o poniendo circunstancias, se envolviesse últimamente en alguna de las fábulas de el gentilismo [...]. Pero no es lo mismo pretender que una u otra fábula se derive de la historia sagrada, que hacer de esta derivación systema general para todos los errores de el paganismo. $\mathrm{Y}$ aun respecto de essas pocas fábulas, se debe proponer la derivación como probable, no como cierta, por la razón [...] de que pudo ser casual la semejanza del error a la verdad.

Sin embargo, Feijoo era consciente de estar atacando de frente una tradición muy arraigada; y, por otra parte, era de esperar que sus adversarios y detractores lo acusaran de escepticismo sistemático y, sobre todo, que pusieran en tela de juicio su respeto a la Biblia. Al refutar esa teoría de un cómodo monoteísmo original cuya prueba se encontraría en las fábulas del paganismo, el benedictino atraía inevitablemente sobre sí el reproche de impiedad.

En efecto, a pesar de la conclusión matizada y razonable del discurso

1s Ibid.: "Fertur Prometheus hominem de luto finxisse, fabula inde ducta, quod hominis originem primus Moses literis consignarit, eumque de terra a Deo formatum esse homines docuerit". 
publicado en el Teatro crítico, Feijoo no tardó en sentir la necesidad de justificarse o, al menos, de ocuparse de nuevo del asunto y poner los puntos sobre las ies: es lo que hizo en la $42^{\text {a }}$ de las Cartas eruditas.

Me han acusado - comienza- de ser un impío porque me he negado a admitir que todas las fábulas mitológicas tuvieron su origen en la Escritura. Eso es traicionar mi pensamiento: "Mi asunto en aquel Discurso es impugnar el sistema que generalmente deriva todas las ficciones gentílicas de la historia sagrada; pero dejando lugar a que algunas de ellas tengan ese origen, como pronuncio claramente al núm. 43, ¿es esto afirmar que ninguna ficción del gentilismo tubo origen de la historia sagrada, como V.mrd. me imputa?"

Tras esta aclaración, Feijoo se pone a demostrar que no es enemigo de un sistema en particular, sino de los sistemas en general. Ha refutado las teorías de un Huet y de un Tournemine. Bien. Pero tampoco acepta sin más el evemerismo riguroso del italiano Bianchini, que llega al extremo de sostener, por ejemplo, que la Iliada es una historia verdadera en sus menores detalles, que en ella los dioses representan a reyes y a señores principales, y las diosas a naciones (Minerva a Egipto, Juno a Siria, etc.). Semejante conclusión le parece contraria al sentido común: "A tan estrañas paradoxas conduce tal vez la passión por los sistemas de mucha amplitud". ¿Quiere eso decir que haya que rechazar en bloque la exegesis evemerista? Claro que no, como tampoco hay que excluir toda identificación con los personajes de la Biblia: "Es sumamente verisímil que algunos de los dioses subalternos fueron formados sobre la idea, que quedó en los pueblos, de algunos personajes insignes o ya por sus virtudes heroicas, o ya por inventores de algunas artes mui útiles al mundo". Por ejemplo, dice Feijoo, es probable que la historia de la barca de Caronte sea un recuerdo contrahecho de la costumbre egipcia de transportar, de una orilla a otra de un lago, cadáveres embalsamados que se llevaban a sepultar; es probable también que, en su origen, los centauros no sean sino los notables jinetes de Tesalia, etc. Por último, Feijoo asegura que no desconoce tampoco los otros modos de explicación de las fábulas: el de Bochart, que pretende explicarlo todo por la etimología fenicia; el de los platónicos, que entienden los mitos como principios de filosofía natural; el de la interpretación moral y alegórica ${ }^{19}$; el de los alquimistas, que buscan en ellos el secreto de la piedra filosofal ${ }^{20}$. En todas partes, concluye, puede haber algo de verdad: lo único condenable es el espiritu de sistema.

Como se ve, la concepción de la mitología que expone Feijoo está de acuerdo con la que tenía de la ciencia y de la historia en general. De allí que estas consideraciones no adquieran toda su originalidad y todo su relieve en el seno de las teorías del benedictino, sino más bien en relación con toda la exegesis mitológica en el estado en que se hallaba en el siglo xvin. Sin duda Feijoo no se encuentra absolutamente solo;

19 Ejercida por Dupuis (Origine de tous les cultes ou Religion universelle), Bergier (L'origine des dieux du paganisme), Court de Gébelin (Le monde primitif), etc.

20 Por ejemplo, Dom Pernety, con sus Fables égyptiennes et grecques dévoilées et réduites au même principe, o su Dictionnaire mythico-hermétique. 
en efecto, no dejó de haber protestas entre los exegetas, y uno de los más famosos, el abate Banier, escribía que "vouloir tirer le dénouement de presque toutes les fables, de l'abus prétendu des livres de Moïse, c'est vouloir s'aveugler", mientras que un Guérin du Rocher trata de quimérico el deseo de dar con un personaje histórico tras cada héroe de la fábula. Pero es verdad también que el relativismo de estos hombres se detenía allí: el primero no creía más que en el evemerismo, el segundo se aferraba tenazmente a la tesis del "plagio bíblico"21.

La superioridad de Feijoo consiste, por el contrario, no en haber inventado un nuevo sistema de explicación, sino en enseñar la desconfianza para con todos los sistemas. Él profesa un atenerse al ejercicio de la razón, al sentido común, a una crítica severa de la verosimilitud y del método, quizá precisamente porque juzga que la mitología, como la historia, es un testimonio del pasado al cual conviene aplicar los criterios del método histórico. Más abierto en esto que un Fontenelle, que veía en las fábulas "la historia de los errores del espíritu humano", pero rechazando los sistemas generales que encarcelan el espíritu, no quiere tampoco que se vea en él a un destructor paralizado por un estéril escepticismo. Su examen de la exegesis mitológica confirma, pues, esa certeza de no poder llegar a verdades únicas y definitivas; como escribía en sus "Reflexiones sobre la historia" (Teatro, t. 4, p. 220), es dificilísimo

no sólo apurar lo cierto, mas aun señalar lo más verisímil en la historia. No por esto aspiro al pyrrhonismo, o pretendo una general suspensión de assenso a quanto dicen los historiadores. Tiene mucha latitud la desconfianza, de modo que, colocada en un grado, es discreción, y en otro, necedad. Es menester buscar con gran tiento los límites hasta donde puede extenderse la duda. Pero ha de procurar salir de ella, siempre que se pueda, o por el camino de la verdad, o por la senda de la verisimilitud.

Así, pues, la crítica de la exegesis mitológica por Feijoo es la de un espíritu abierto y lúcido, que lucha por liberarse de los prejuicios y de las ataduras intelectuales; en este sentido, es una nueva piedra de toque de su método general y se inscribe en el contexto de su pensamiento entero"2. Como se ha dicho ya, "Feijoo, a diferencia de otros autores del siglo xvin, supo unir el sentido de la renovación más audaz, con la continuación de elementos tradicionales dignos de ser conservados" 23. Sin duda, la opinión del autor del Teatro crítico sobre la interpreta-

${ }^{21}$ Sobre el estado de la exegesis mitológica en el siglo xvm, véase J. Deshayes, "De l'abbé Pluche au citoyen Dupuis: à la recherche de la clef des fables", Transactions of the First International Congress on the Enlightenment, 1963, t. 1, pp. 457-486, y nuestro libro Le thème de Prométhée dans la littérature européenne, Genève, 1964 , t. 1 , pp. $181-187$.

22 Tanto más curioso resulta el que Feijoo no sea citado ni por A. Pinard de LA Boullaye, L'étude comparée des religions, Paris, 1925, ni por $\mathrm{O}$. Gruppe, op. cit., y que su interés por la mitología no sea ni siquiera evocado en los trabajos de $G$. DELPY, Bibliographie des sources françaises de Feijoo, Paris, 1936, y L'Espagne et l'esprit européen. L'œuvre de Feijoo, Paris, 1936, ni en el libro de F. E. Manuel, The eighteenth century confronts the Gods, Cambridge, Mass., 1959.

23 A. Valbuena Prat, Historia de la literatura española, $5^{\text {a }}$ ed., Barcelona, 1957 , t. 3, p. 186 . 
ción de las fábulas no es sino un aspecto del conjunto de su crítica; para captar toda su originalidad, conviene situarlo en el complejo marco de la exegesis dieciochesca: sólo así podrá aparecer como un nuevo "desengaño de errores comunes" -y un desengaño nada despreciable. En este, como en tantos otros campos, Feijoo podía reivindicar como adquirido el resultado que, no sin orgullo, proclamaba en el prólogo del cuarto tomo de su Teatro: "Di lo que quisieres, no podrás negarme la novedad de esta obra, la cual me da el carácter de autor original [...]. Tampoco podrás negar que el designio de impugnar errores comunes, sin restricción de materias, no sólo es nuevo, sino grande".

R. Trousson

Université Libre de Bruxelles.

\section{JOSÉ MARÍA HEREDIA Y JOSÉ DE ESPRONCEDA: ¿UNA GONEXIÓN DIRECTA?}

Hay en la poesía de José María Heredia una sorprendente semejanza con la de José de Espronceda. Sorprendente, entre otras cosas, porque ningún investigador, que yo sepa, la ha señalado ni mucho menos estudiado, por más que la crítica está de acuerdo en que la vida de los dos poetas tuvo mucho en común, lo cual explicaría, en parte, las semejanzas de su obra. Empecemos por destacar esas analogías extrapoéticas antes de pasar a la poesía misma.

Heredia y Espronceda, contemporáneos (nacido el primero en $180 \mathrm{og}$, el segundo en 1808), experimentaron por igual la influencia de Byron, como dicen las historias literarias, y los dos abrazaron la ideología del liberalismo político de su época; ambos pertenecieron a organizaciones liberales muy activas, Heredia a la de los "Caballeros racionales" y Espronceda a la de los "Numantinos" causa de las actividades políticas que desarrollaron en esas organizaciones; los dos, finalmente, escribieron poemas patrióticos de fuerte inspiración liberal (Heredia, "Al sol", "Himno del desterrado"; Espronceda, "Al dos de mayo", "A la patria").

Tales analogías bastan para explicar ciertos hilos comunes en la poesía del cubano y del español, pero no para explicar lo que es a menudo una correspondencia exacta de temas y hasta de palabras, correspondencia que me propongo mostrar comparando el "Niágara" de Heredia con el "Himno al sol" de Espronceda ${ }^{2}$. Como el "Himno al sol"

1 Tanto los "Caballeros racionales" como los "Numantinos", productos del exaltado liberalismo de principios del siglo $\mathrm{xIX}$, lucharon por varios medios contra el gobierno reaccionario de Fernando VII, y sufrieron la consiguiente persecución. Sobre la relación de los dos poetas con las respectivas organizaciones, véanse las siguientes obras: Rafael Estenger, Heredia: la incomprensión de si mismo, La $\mathrm{Ha}$ bana, 1938, cap. 3; José María Chacón y Calvo, Estudios heredianos, La Habana, 1939, pp. 102-111; Jorge Campos, Espronceda, Madrid, 1963, p. 30; Vicente Llorens, Liberales y románticos, El Colegio de México, 1954, p. 32.

2 "Niágara", escrito el 15 de junio de $1_{24}$, se publicó en la 1 ạ ed. de las obras de Heredia, hecha en Nueva York en 1825. La 2a ed., impresa en México en 1832 , 